\title{
Defluoridation of Water Using Natural and Activated Coal
}

\author{
Merga Regassa ${ }^{1}$, Fekadu Melak ${ }^{2}$, Wondessen Birke ${ }^{2}$, Esayas Alemayehu ${ }^{1}$ \\ School of Civil and Environmental Engineering, Institute of Technology, Jimma University, Jimma, Ethiopia ${ }^{1}$ \\ Dept of Environmental Sciences and Technology, College of Public Health and Medical Sciences, Jimma University ${ }^{2}$
}

\begin{abstract}
High fluoride concentration is a worldwide problem in drinking water due its health effects. Batch mode investigation to remove fluoride from aqueous solution and real groundwater samples by natural coal and its modified forms was made. The physicochemical analysis of adsorbents and their activation was overseen to well understand the mechanism of sorption. Adsorption was found to be $\mathrm{pH}$ dependent with optimal removal efficiency at $\mathrm{pH} 2$ for physically and chemically activated coal and at $\mathrm{pH} 4$ for natural coal (NC). The experimental data was well fitted with Langmuir and Freundlich adsorption model providing maximum adsorption capacity of 5.9, 8.36 and $11.35 \mathrm{mg} / \mathrm{g}$ for natural, physical and chemical activated coal in their order written from Langmuir model. The Dubinin-Radushkevich isotherm $\left(R^{2}=0.988\right)$ with mean free energy $(E=0.085 \mathrm{KJ} / \mathrm{mol})$ for natural coal signify physiosorption should be mainly responsible for fluoride adsorption. The applicability of the adsorbents from fluoride contaminated groundwater indicated that natural coal (NC), physically activated coal (PAC) and chemically activated coal (CAC) can be used as an effective, low-cost adsorbent to remove fluoride from groundwater. The buffering capacity of adsorbents monitored during sorption induces a $\mathrm{pH}$ increase to nearly neutral, after sorption, which may be an important asset in real applications.
\end{abstract}

Key words: Natural coal, Adsorption isotherms, Defluoridation

\section{INTRODUCTION}

Fluoride pollution of groundwater in lesser extent surface water, mostly from geogenic sources is a global concern. High or low concentrations of fluoride can occur depending on the nature of the rocks and occurrence of fluoride bearing minerals. Fluoride could be common in groundwater which calcium are found to be poor in aquifers[1-3]. It is often described as a "double-edged sword" as inadequate ingestion, less than or equal to 0.5 $\mathrm{mg} / \mathrm{L}$ in drinking waters, which could be associated with dental caries whereas excessive intake, greater than 1.5 $\mathrm{mg} / \mathrm{L}$, leads to dental, skeletal and soft tissue fluorosis. Excess fluoride in drinking water occurs in many countries due to natural and anthropogenic sources. More than 200 million people worldwide, of which about 8 million inhabit in the Main Ethiopian Rift Valley (MER), rely on groundwater for drinking and domestic applications, are exposed to naturally elevated fluoride levels, inducing health risks for the local population[4,5].

Various defluoridation technologies have been developed to mitigate excess fluoride from drinking water before consumption. These methods include chemical precipitation, coagulation and electrocoagulation [6] ion exchange[7,8], membrane process[9], and adsorption techniques[10]. However, most of the removal techniques whether conventional or advanced suffer from different shortcomings especially in the developing globe. This is due high energy requirements, cost unaffordability, and large quantities of sludge production that again needs safest disposal, fouling through the way of implementation, requirement of skilled labor, extensive pretreatment and prone to chemical hazardous[11-16]. Among several treatment technologies applied for fluoride removal, adsorption process has been explored widely and offers satisfactory results. Many natural and low cost materials such as sorption by activated alumina [17,18], activated carbon, aluminum (hydr)oxide, bone char, various types of clays, termite mound[19,20] have been employed. However, still there is a need to find out practical and/ or affordable utility adsorbents on a commercial scale, leading to the improvement of pollution control. A high adsorbent-adsorbate affinity is essential for sorption processes to be efficient. Apatite and bone char and related adsorbents are found to be high affinity with fluoride ions. However, availability and cultural taboo involved are common limitations. Thus, consideration of naturally occurring and abundantly available adsorbents which possess high affinity with the adsorbate, as a replacement for high-cost adsorbents, is highly important in developing countries.

Accordingly, the major objective of the present work was to assess the potential of natural coal from Ethiopia and its activated forms, to remove fluoride from water. Therefore, batch sorption experiments were conducted under different conditions and sample ground water was tested in a batch system using these adsorbents.

\section{MATERIALS AND METHODS}

\subsection{Adsorbent processing and characterization}

In this study, coal samples utilized as adsorbent were collected from Dilbi, Ethiopia. The samples of adsorbents were taken from three seams of the stratification of Dilbi coal mining site. The three seams of stratified bituminous coal sample were washed independently to remove fine impurities by distilled water. 
The air dried adsorbents were washed with warm distilled Then volume $\mathrm{V}$, required to raise the $\mathrm{pH}$ from 4 to 9 was water followed by de-ionzed water and dried at $105{ }^{\circ} \mathrm{C}$ for recorded. The surface area $\mathrm{S}$ was calculated from the 24 hours in an oven. Finally the coal was grinded to equation: granular size of each seam separately.

\subsection{Preparation of natural coal (NC) adsorbent}

Equal proportion of each three seam (1:1:1) was used and sieved to the mesh size of $<150 \mu \mathrm{m}$ and the product was stored in a plastic bags for further application.

\subsubsection{Physical activation}

Coal samples were physically activated according to litratures $[21,22]$ with some amendment. The processed NC (250 g from three seams) was mixed and filled in a steel container with a tight lid. Activation of natural coal setup in a muffle furnace for a temperature rise of $2{ }^{0} \mathrm{C} /$ minute then with a hold time of $1 \mathrm{~h}$ at $850{ }^{\circ} \mathrm{C}$. After cooling, the carbon was taken out and sieved to < $150 \mu \mathrm{m}$ size and designated as physically activated carbon (PAC) and stored in air tight plastic containers.

\subsubsection{Chemical activation}

The chemical activated coal is prepared according to [23] except the use of $\mathrm{NaOH}$ in place of $\mathrm{KOH}$. Chemical activations were carried out by physical mixing of $\mathrm{NaOH}$ and natural coal material with a $\mathrm{NaOH} /$ natural coal ratio of $2: 1$ (wt/wt). Finally dried for $2 \mathrm{hr}$ in $105^{\circ} \mathrm{C}$ in an oven. The resulting product was sieved to the mesh size of $<150 \mu \mathrm{m}$.

\subsection{Determination of $\mathrm{pH}$ and conductivity of} adsorbents

$1.0 \mathrm{~g}$ of coal was weighed and transferred into a $250 \mathrm{ml}$ beaker and $100 \mathrm{ml}$ of distilled water was added and stirred for $1 \mathrm{hr}$ using magnetic stirrer. Samples were allowed to stabilize and then $\mathrm{pH}$ measured using an electronic $\mathrm{pH} /$ Conductivity meter (HQ40D multi parameter model).

\subsection{Determination of pore volume}

The pore volume was determined according to ASTM D3766, considering $1 \mathrm{~g}$ coal sample which was immersed in water bath and boiled for 15 minutes in order to displace air from the pores. The pore volume was calculated as increase in weight $(\partial \mathrm{w})$ divided by the density of water at $25 \mathrm{~cm}^{3}$.

\subsection{Determination of bulk density}

The bulk density was determined according to ASTM D2854-96 provided that $25 \mathrm{~cm}^{3}$ density bottles was weighed and the coal sample was packed by repeatedly tapping the bottle so that the powder is filled up to the mark.

\subsection{Surface area determination}

Sears' titration method was used for the determination of surface area of raw adsorbent [24-26]. $0.5 \mathrm{~g}$ of the three adsorbent was weighed and acidified with $0.1 \mathrm{M} \mathrm{HCl}$ from $\mathrm{pH} 3$ to 3.5. Then $30 \mathrm{~g}$ of $\mathrm{NaCl}$ was added and the volume was made up to $50 \mathrm{~mL}$ with distilled water. The titration with standard $0.1 \mathrm{M}$ of $\mathrm{NaOH}$ was carried out from $\mathrm{pH} 4$ to $\mathrm{pH} 9$.

$$
\mathrm{S}\left(\mathrm{m}^{2} / \mathrm{g}\right)=32 \mathrm{~V}-25
$$

\subsection{Reagents}

A $1000 \mathrm{mg} / \mathrm{L}$ fluoride stock solution was prepared by dissolving $2.21 \mathrm{~g}$ of anhydrous sodium fluoride (BDH Chemicals Ltd Poole, England) in $1000 \mathrm{ml} \mathrm{de-ionized}$ water in volumetric flask. Then this stock solution was stored in a polyethylene bottle for further use. Alizarin Red $\mathrm{S}$ and zirconyl acid solution preparation was made according to [27] for spectroscopic determination of fluoride.

\subsection{Batch adsorption experiments}

Batch adsorption experiments with blank (NC, PAC and $\mathrm{CAC}$ in de-ionized water) and positive control (aqueous solution with no addition of adsorbents, only with fluoride) were carried out to investigate the adsorption process of fluoride on $\mathrm{NC}, \mathrm{PAC}$ and $\mathrm{CAC}$ under various experimental condition.

The natural and activated coals was equilibrated on a horizontal mechanical shaker (SM-30, Edmund Bühler $\mathrm{GmbH}$, Germany) with $100 \mathrm{ml}$ of known concentration of fluoride within an acid washed polyethylene $250 \mathrm{ml}$ plastic flasks at room temperature of $\left(24 \pm 2{ }^{0} \mathrm{C}\right)$. Then, filtration was made quickly through a filter paper with a diameter of $0.125 \mu \mathrm{m}$ (Sartorius 37075 Göttingen, Germany). The filtrates were analyzed using spectrophotometer HACH (LANGE) DR 5000 single beam at a wavelength of $520 \mathrm{~nm}$. The fluoride adsorption capacity by the adsorbent material was calculated using following equation:

$$
q_{\mathrm{e}}=\frac{\left(C_{\mathrm{o}}-C_{\mathrm{e}}\right) V}{W}
$$

where $\mathrm{q}_{\mathrm{e}}$ is the amount of fluoride removed from solution $(\mathrm{mg} / \mathrm{g}) ; \mathrm{C}_{0}$ is initial concentration of fluoride in solution before mixing with adsorbent $(\mathrm{mg} / \mathrm{L}) ; \mathrm{C}_{\mathrm{eq}}$ is the equilibrium concentration of fluoride left in the solution after the experiment $(\mathrm{mg} / \mathrm{L}) ; \mathrm{V}$ is the solution volume $(\mathrm{L})$, and $\mathrm{W}$ is the weight of adsorbent in $(\mathrm{g})$.

\section{RESULTS AND DISCUSSION}

\subsection{Characterization of adsorbents}

The physicochemical analysis of coals was carried out by using standard method (ASTM D5142-90). The results of analysis were presented in Table 1 below. It seems from the result that the surface area has indications in sorption increment order of fluoride uptake by adsorbents.

The results of chemical composition of natural coal are given in Table 2. It is noted that the sum of iron, aluminum, magnesium and calcium oxides are significantly high and together amounted to nearly 45 wt. $\%$, plus relatively higher amount of carbon content was the reason which could lead to high sorption of fluoride anion. 
Table1. Physicochemical properties of coal used in the adsorption of fluoride

\begin{tabular}{|c|c|c|c|c|c|c|}
\hline Adsorbent & & & & & & \\
\hline & $\mathrm{pH}$ & $\begin{array}{l}\text { Electric } \\
\text { conductive } \\
(\mu \mathrm{s} / \mathrm{cm})\end{array}$ & $\begin{array}{l}\text { Bulk Density } \\
\left(\mathrm{g} / \mathrm{cm}^{3}\right)\end{array}$ & $\begin{array}{l}\text { Specific density } \\
\left(\mathrm{g} / \mathrm{cm}^{3}\right)\end{array}$ & $\begin{array}{l}\text { Moistue } \\
\text { content }(\%)\end{array}$ & $\begin{array}{l}\text { Surface } \\
\left(\mathrm{m}^{2} / \mathrm{g}\right)\end{array}$ \\
\hline $\mathrm{NC}$ & 8.10 & 69.40 & 0.65 & 164 & 4.19 & 227.58 \\
\hline PAC & 9.19 & 105.2 & 0.64 & 18 & 0.58 & 312 \\
\hline CAC & 10.62 & 225 & 0.80 & 6 & 5.23 & 711 \\
\hline
\end{tabular}

Similar results have observed with similar Further increase in contact time does not show an increase adsorbents[28,29]. in the uptake of fluoride ions. The reason could be

Table2. Chemical characteristics of natural coal

\begin{tabular}{ll|ll}
\hline \multicolumn{2}{l}{ Total elements (\%) } & \multicolumn{2}{c}{ Ash Chemistry/Oxides } \\
\hline Carbon & 51.51 & $\mathrm{Fe} 2 \mathrm{O} 3$ & 6.85 \\
Hydrogen & 4.42 & $\mathrm{Al} 2 \mathrm{O} 3$ & 34.17 \\
Nitrogen & 0.96 & $\mathrm{CaO}$ & 1.42 \\
Sulfur & 0.56 & $\mathrm{MgO}$ & 0.71 \\
Oxygen & 12.51 & $\mathrm{SiO} 2$ & 54.56 \\
& & $\mathrm{SO} 3$ & 0.90 \\
\hline
\end{tabular}

Source: Raw data taken from Dilbi Coal Mining Share Company, (2008) with letter permission

\subsection{Effect of contact time}

Time is an essential parameter to be considered in the study to evaluate the kinetic aspect of sorption. Adsorption of fluoride by NC, PAC and CAC was studied within a time period of 5-180 min. in Fig. 1. It is found that initially a fast removal efficiency of fluoride ions was observed increasing with increase in contact time. After 15 minutes, a gradual increment was observed, then after, approaching a constant value, signifying equilibrium has reached at 60 minute for $\mathrm{NC}$ and $\mathrm{PAC}$ but at 90 minute for $\mathrm{CAC}$ with the maximum efficiency of $82 \%, 86 \%$ and 90 $\%$, respectively.

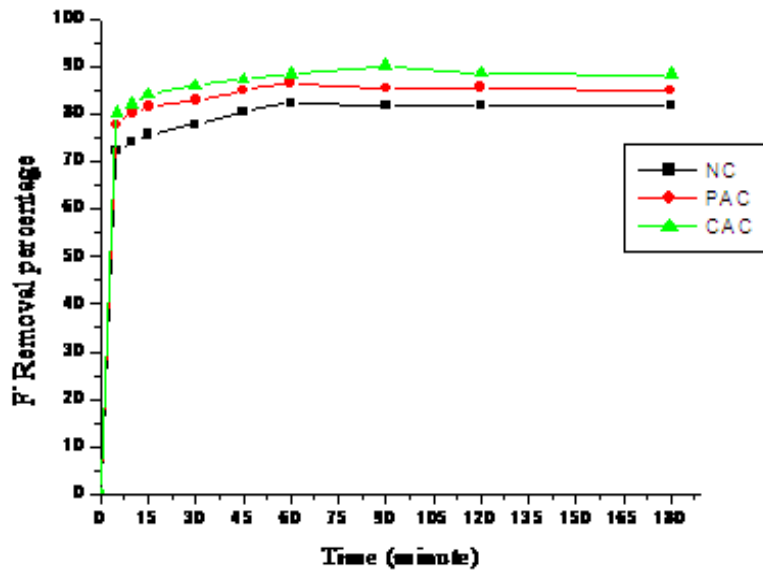

Fig.1. Effect of contact time on fluoride removal (initial concentration: $5 \mathrm{mg} \mathrm{L}^{-1}$; $\mathrm{pH}$ : 4.53 ; adsorbent dose: 0.3 $\mathrm{g} / 100 \mathrm{ml}$; agitation: $150 \mathrm{rpm})$. attributed to the availability of high surface area as well as porous structural features facilitating easy removal of fluoride [30]. It may be noted that the nature of the pores in the sorbent also determines the magnitude of contact time for attainment of equilibrium [31].

\subsection{Effect of pH}

The $\mathrm{pH}$ of the solution is an important parameter in the adsorption process. The influence of initial solution $\mathrm{pH}$ on the fluoride removal efficiency of $\mathrm{NC}, \mathrm{PAC}$ and $\mathrm{CAC}$ adsorbents was illustrated in Fig. 3. The pH of a solution affects the surface charge of the adsorbent material. In lower $\mathrm{pH}$ ranges, the surface of the adsorbents could be positively charged, which leads to the specific adsorption of fluoride on metal oxides of coal or partially positive charge of carbon due to the electrostatic interaction between positively charged adsorbents surface and negatively charged fluoride ions. Whereas, removal efficiency decreased as initial $\mathrm{pH}$ increased. The decrement in the removal of $\mathrm{F}^{-}$at higher $\mathrm{pHs}$ than $\mathrm{pHzc}$ of sorbents is attributed to the increase in number of negatively charged sites on the surface of the adsorbents.

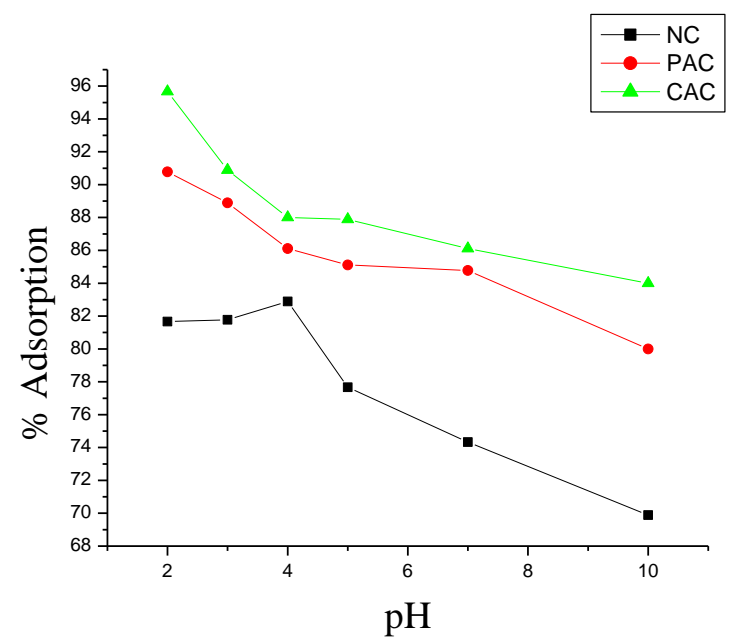

Fig. 3 Effect of $\mathrm{pH}$ on fluoride removal (initial concentration: $5 \mathrm{mg} \mathrm{L}^{-1}$; Contact time: 60 minute for $\mathrm{NC}$ and PAC, 90 minute for CAC; adsorbent dose: $0.3 \mathrm{~g} / 100$ $\mathrm{ml}$; Agitation speed: $150 \mathrm{rpm})$.

Thus, the enhanced electrostatic repulsion plus the potential competition of fluoride with hydroxyl ions for absorption to the surface should be responsible for the 
decreased removal of fluoride at higher $\mathrm{pH}$ ranges. Thus aforementioned cases might be due both $\mathrm{OH}^{-}$and $\mathrm{F}^{-}$are is electronic and have the same charge and similar ionic radii [32-34].

Moreover, coal-based sorbents contain $\mathrm{OH}^{-} \& \mathrm{COOH}$ functionalities, imparting ion-exchange properties[11]. Presumanly the adsorption mechanism of bitminous coal adsorbent used could be proposed as in eq. (3-5) [11] :

and/or[35]

$$
\begin{aligned}
& >\mathrm{C}=\mathrm{O} \cdots \mathrm{H}-\mathrm{F} \\
& >\mathrm{C}-\mathrm{O}-\mathrm{H}^{\cdots \cdots} \mathrm{F}-\mathrm{H} \\
& >\mathrm{C}-\mathrm{O}-\mathrm{H}^{\cdots} \mathrm{F}^{-}
\end{aligned}
$$

$$
>\mathrm{MOH}+\mathrm{F}^{-}+\mathrm{H}^{+} \leftrightarrow>\mathrm{MF}+\mathrm{H}_{2} \mathrm{O}
$$

\subsection{Effect of adsorbent dose}

The adsorbent doses $(0.1$ to $2.5 \mathrm{~g} / 100 \mathrm{ml})$ were studied to see the effect on fluoride adsorption keeping other parameters at optimum conditions(Fig. 4, $5 \mathrm{a} \& \mathrm{~b}$ ). The adsorption efficiency of fluoride increases with increasing adsorbents dose. The increase in the adsorption efficiency with an increase in the adsorbent dose can be attributed to the increase due active adsorption sites. Whereas fluoride adsorption capacity decreases with an increase of adsorbents amount. Such decrement in sorption capacity is attributed to the fact that fluoride is diluted over the surface of the adsorbent when the amount of adsorbent is further increased.

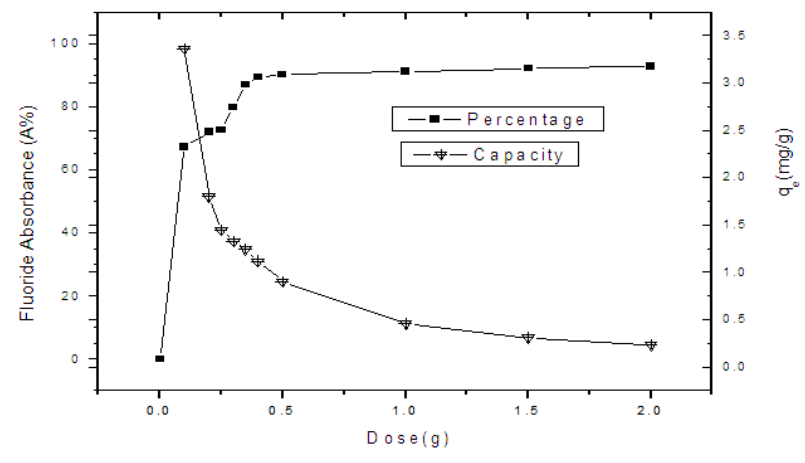

Natural Coal

Fig. 4. Effect of adsorbent dosage on fluoride ions adsorption and adsorption capacity (conditions for (a) NC initial concentration; $5 \mathrm{mg} \mathrm{L}^{-1}$; contact time: 60 minute, adsorbent dose: $0.3 \mathrm{~g} / 100 \mathrm{ml}$; $\mathrm{pH} 4$ agitation speed of 175 rpm

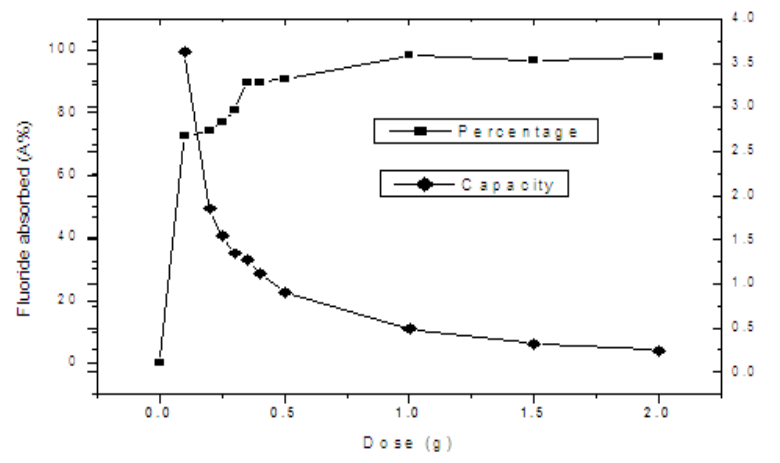

a) Chemical activated coal

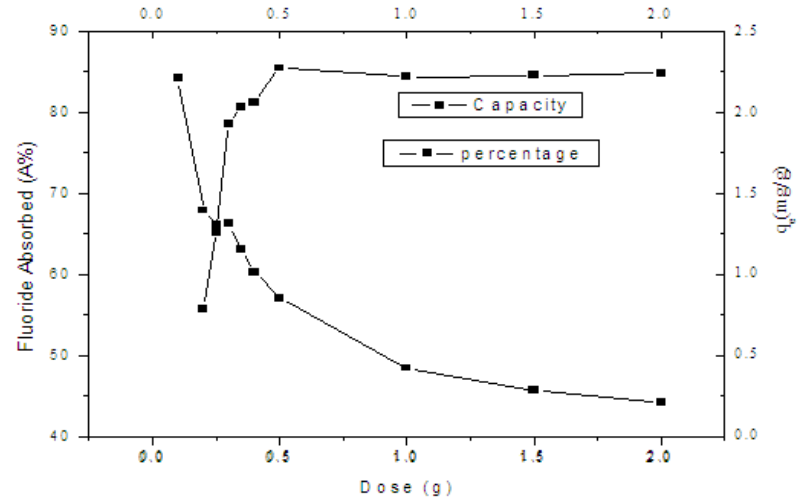

b) Physical activated coal

Fig.5 Effect of adsorbent dosage on fluoride ions adsorption and adsorption capacity (conditions for (a) PAC initial concentration; $5 \mathrm{mg} \mathrm{L}^{-1}$; contact time: 60 minute,; pH 2, agitation speed of $175 \mathrm{rpm}$ (b) CAC initial concentration; $5 \mathrm{mg} \mathrm{L}^{-1}$; contact time: 90 minute; $\mathrm{pH} 2$ agitation speed of $200 \mathrm{rpm}$ average data for duplicate measurement

\subsection{Effect of initial concentration}

The percentage removal of fluoride was studied by varying fluoride ion concentration from 2 to $25 \mathrm{mg} \mathrm{L}^{-1}$ keeping other parameters at optimum conditions. The sorption capacity of the three adsorbents increases with an increase in the initial fluoride concentrations.

\subsubsection{Adsorption Isotherm}

The Langmuir and Freundlich adsorption isotherm models are widely used to describe adsorption data[36]. The Langmuir model [37] is based on the assumption that the maximum adsorption occurs when a saturated monolayer of solute molecules is present on the adsorbent surface, the energy of adsorption is constant, and there is no migration of adsorbate molecules in the plane of the surface[38]. Adsorption can only occur at finite (fixed) number of definite localized sites, that are identical and equivalent with lateral interaction and steric hindrance between the adsorbed molecules, even on adjacent sites [39]. The Langmuir isotherm model equation is given in the equation below:

$$
q e=\frac{c_{e} k_{a} q_{m}}{1+k_{a} C_{e}}
$$

In its linear form it is given by the following equation:

$$
\frac{1}{Q_{e}}=\frac{1}{\left(K_{a} Q_{m}\right)} \cdot \frac{1}{C_{e}}+\frac{1}{Q_{m}}
$$

Where $\mathrm{C}_{\mathrm{e}}$ is the equilibrium concentration $\left(\mathrm{mg} \mathrm{L}^{-1}\right)$; Qe is the amount of ion adsorbed (mg/g); Qm is the monolayer capacity of the adsorbent $(\mathrm{mg} / \mathrm{g}) ; \mathrm{Ka}$ is adsorption equilibrium constant $(\mathrm{L} / \mathrm{mg})$. The constants $\mathrm{Q}_{\mathrm{m}}$ and $\mathrm{K}_{\mathrm{a}}$ can be determined from a linearized form Eq. (10) by the slope of the linear plot of Ce/Qe versus Ce. Plotting Ce vs. $\mathrm{Ce} / \mathrm{Qe}$, the Langmuir constants, $\mathrm{Qm}$ and $\mathrm{b}$ can be determined from the slope and intercept. The results of adsorption isotherm analysis were summarized in Table 5. 
Freundlich isotherm model of adsorption relation in nonlinearized form can be expressed as:

$$
q_{e}=K_{F} C_{e^{\frac{1}{n}}}
$$

Where qe is the amount of ion adsorbed $(\mathrm{mg} / \mathrm{g})$; $\mathrm{Ce}$ is the equilibrium concentration $\left(\mathrm{mg} \mathrm{L}^{-1}\right) ; \mathrm{K}_{\mathrm{F}}$ and $1 / \mathrm{n}$ are empirical constants, indicating the adsorption capacity and adsorption intensity, respectively. $\mathrm{Kf}$ and $\mathrm{n}$, which respectively indicate the adsorption capacity and the adsorption intensity, were calculated from the intercept and slope of lnqe versus lnCe. Eq. (12) can be written in linear form:

$$
\operatorname{logqe}=\log \mathrm{K}_{\mathrm{f}}+\frac{\mathbf{1}}{\mathbf{n}} \log \mathrm{C}_{\mathrm{e}}
$$

The plot of $\log \mathrm{q}_{\mathrm{e}}$ versus $\log \mathrm{C}_{\mathrm{e}}$ of Eq. (10) should result in a straight line. From the slope and intercept of the plot, the values for $\mathrm{n}$ and $\mathrm{K}_{\mathrm{F}}$ can be obtained.
The Freundlich isotherm is nearly fitting model for the data.

The Temkin isotherm has been used in the following form:

$$
\mathrm{qe}=\frac{\text { RTInACe }}{\mathrm{b}}
$$

$B=\frac{R T}{b}$

Temperature $(\mathrm{K}$

$\mathrm{R}$ is gas constant $(8.314 \mathrm{~J} / \mathrm{mol} / \mathrm{K}), \mathrm{T}$ is

The sorption data can be analyzed from the linearized equation above. Therefore a plot of qe versus $\operatorname{lnCe}$ enables one to determine the constants $\mathrm{A}$ and $\mathrm{B}$. The values of the Temkin constants A and B are listed in Table 3. The correlation coefficient of 0.992 obtained showed that adsorption of $\mathrm{F}^{-}$also followed Temkin model. The Langmuir, Freundlich and Temkin adsorption constants calculated from the corresponding isotherms with the correlation coefficients are presented in Table 5.

Table 3 Parameters of adsorption isotherms

\begin{tabular}{llllllllllll}
\hline & \multicolumn{3}{l}{ Adsorbtion Isotherms } \\
& \multicolumn{3}{l}{ Langmuir } & \multicolumn{3}{c}{ Freundlich } & \multicolumn{4}{c}{ Temkin } \\
\cline { 2 - 10 } Adsorbent & $\mathrm{q}(\mathrm{mg} / \mathrm{g})$ & $\mathrm{K}_{\mathrm{a}}(\mathrm{L} / \mathrm{mg})$ & $\mathrm{R}^{2}$ & $\mathrm{Kf}(\mathrm{L} / \mathrm{mg})$ & $1 / \mathrm{n}$ & $\mathrm{R}^{2}$ & $\mathrm{bT}(\mathrm{kJ} / \mathrm{mol})$ & $\mathrm{R}^{2}$ \\
\hline $\mathrm{NC}$ & 5.9 & 0.17 & 0.992 & 1.74 & 0.58 & 0.976 & -1.7 & 0.978 & 0.99 \\
PAC & 8.36 & 0.43 & 0.994 & 2.3 & 0.65 & 0.98 & -1.81 & 0.99 & \\
CAC & 11.35 & 0.64 & 0.998 & 1.9 & 0.786 & -3.189 & 0.98 & \\
& & & & & 0.98 & & & \\
\hline
\end{tabular}

In order to find out the feasibility of isotherm, the essential equilibrium solid concentration $\left(\mathrm{g} \mathrm{L}^{-1}\right)$. $\mathrm{K}$ is the constant characteristics of Langmuir isotherm can be expressed of a related to adsorption energy. $\mathrm{R}$ is the gas constant and $\mathrm{T}$ in dimensionless constant separation factor or equilibrium this study was $(298 \mathrm{~K})$ temperature in Kelvin. The value of parameter $\mathrm{R}_{\mathrm{L}}$ [40]. Thus, $\mathrm{R}_{\mathrm{L}}$ can be expressed as:

$$
\mathrm{R}_{\mathrm{L}}=1 /\left(1+\mathrm{K}_{\mathrm{L}} \mathrm{Co}\right)
$$

where, Co is the initial concentration of fluoride $\left(\mathrm{mg} \mathrm{L}^{-1}\right)$. $\mathrm{R}_{\mathrm{L}}<1$ represents favorable adsorption. In our case, the value of $\mathrm{R}_{\mathrm{L}}$ for the initial fluoride concentration of $15 \mathrm{mg}$ $\mathrm{L}^{-1}$ was found to be 0.82 by liner regression analysis for natural coal adsorbent indicating a favorable condition of adsorption of fluoride.

Freundlich constants $\mathrm{K}_{\mathrm{F}}$ and $1 / \mathrm{n}$ described about the adsorption capacity and adsorption intensity, respectively. Higher the value of $1 / \mathrm{n}$, the higher will be the affinity between the adsorbate-adsorbent and the heterogeneity of the adsorbent sites.

In order to understand the type of adsorption, the equilibrium data was tested with $\mathrm{D}-\mathrm{R}$ isotherm. The $\mathrm{D}-\mathrm{R}$ isotherm can be represented[40]:

$$
\mathrm{qe}=\mathrm{qm} \exp \left(-\mathrm{K} \varepsilon^{2}\right)
$$

The linearized form of Eq. (12) can be written as:

$$
\ln \mathrm{qe}=\ln \mathrm{qm}-\mathrm{K}^{2}
$$

where, $\varepsilon^{2}$ is the Polanyi potential which is equal to RT $\ln$ $(1+1 / \mathrm{Ce})$. qe is the amount of adsorbate adsorbed at equilibrium per unit of adsorbent $(\mathrm{g} g-1)$, $\mathrm{qm}$ is the theoretical saturation capacity $(\mathrm{g} g-1), \mathrm{Ce}$ is the
$\mathrm{K}$ and $\mathrm{qm}$, respectively, is obtained from the slope and intercept of the plot qe vs. $\varepsilon^{2}$. The D-R constant $\mathrm{K}$ denotes the value of mean free energy of adsorption. The value of E can be computed using the following equation:

$E=(-2 K)^{-0.5}$ Where $K$ is -95.2 from eq.(13) indicating $E$ to be nearly $0.085 \mathrm{KJ} / \mathrm{mol}$. When value of $\mathrm{E}$ is between 8 and $16 \mathrm{~kJ} \mathrm{~mol}^{-1}$, the adsorption type can be represented as an ion-exchange process. Whereas if $\mathrm{E}<8 \mathrm{~kJ} \mathrm{~mol}^{-1}$, it could represent a physical adsorption process.

\section{APPLICATION}

The method under investigation was tested using groundwater samples. Defluoridation of the samples of natural groundwater containing $15.3 \mathrm{mg} \mathrm{L}^{-1}$ fluoride was collected from wells available at Jimma University, Ethiopia. The physicochemical characteristics of the samples are given in Table 4. It was found that under the optimal conditions made in the aqueous system and batch mode 62 and nearly $88 \%$ adsorption was achieved in a $\mathrm{pH}$ range of 5.5-7 in natural and activated carbon adsorbents; $15.3 \mathrm{mg} / \mathrm{L}$ was reduced to 5.814 and $1.836 \mathrm{mg} / \mathrm{L}$ for case of natural coal adsorbent and activated adsorbents, respectively. Although the reduction is high, more than one adsorption step seem to be required for complete treatment to reduce $5.814 \& 1.836 \mathrm{mg} / \mathrm{L}$ fluoride to below the permissible level, $1.5 \mathrm{mg} / \mathrm{L}$ by WHO. 
International Advanced Research Journal in Science, Engineering and Technology

Vol. 3, Issue 1, January 2016

Table 4. Physicochemical characteristics of groundwater at $22.7{ }^{0} \mathrm{C}$

\begin{tabular}{ll}
\hline Parameter & Values \\
\hline $\mathrm{pH}$ & $7.87-7.94$ \\
Conductivity $(\mu \mathrm{S})$ & 1263 \\
Total hardness as $\mathrm{CaCO}_{3}\left(\mathrm{mg} \mathrm{L}^{-1}\right)$ & 692 \\
Chloride $\left(\mathrm{mg} \mathrm{L}^{-1}\right)$ & 5.73 \\
Fluoride $\left(\mathrm{mg} \mathrm{L}^{-1}\right)$ & 16.03 \\
Carbonate & 0.34 \\
Bicarbonate & 690.74 \\
Magnesium & 8.26 \\
\hline
\end{tabular}

The capacities of selected similar adsorbents for sorption of fluoride are summarized in Table $\mathbf{5}$ in relation to different operating conditions for comparison reasons.

Table5. Summary of adsorption capacities of some selected adsorbents

\begin{tabular}{llccc}
\hline Type of adsorbent & Removal capacity $(\mathrm{mg} / \mathrm{g})$ & Ratio of $(\mathrm{S} / \mathrm{L})$ & $\mathrm{pH}$ & Reference \\
\hline Activated red mud & 0.331 & $0.2 \mathrm{~g} / 50 \mathrm{ml}$ & 5.5 & {$[41]$} \\
Original red mud & 0.164 & $0.2 \mathrm{~g} / 50 \mathrm{~mL}$ & 5.5 & {$[41]$} \\
Bone char & 3.96 & & 5 & {$[42]$} \\
Mesoporous alumina & 14.26 & $0.6 / 50 \mathrm{~mL}$ & 6 & {$[43]$} \\
$\quad$ Termite mound & 2.70 & $1.5 \mathrm{~g} / 50 \mathrm{~mL}$ & $3-8$ & {$[28]$} \\
Citrus limonum (lemon) leaf & 0.070 & & 2 & {$[44]$} \\
$\quad$ Graphene & 35.59 & $0.025 \mathrm{~g} / 50 \mathrm{~mL}$ & 7 & {$[45]$} \\
Natural coal(NC) & 5.9 & $1 \mathrm{~g} / 50 \mathrm{~mL}$ & 2 & This study \\
\hline
\end{tabular}

\section{CONCLUSION}

On the basis of experimental findings, it has been concluded that the batch adsorption efficiency and the application on real water showing higher efficiency is important clue to consider the adsorbent further in treatment options. Natural coal from Ethiopia and its modifications were effective for fluoride adsorption in both aqueous solutions and groundwater. It was shown that removal of fluoride using activated coal carbon was highly $\mathrm{pH}$ dependent. The experimental data onto activated coal carbon was well described by Langmuir isotherm more than others described. The DubininRadushkevich isotherm $\left(\mathrm{R}^{2}=0.988\right)$ with mean free energy $(\mathrm{E}=0.085 \mathrm{KJ} / \mathrm{mol})$ for natural coal supporting the Temkin model that physiosorption should be mainly responsible for fluoride adsorption. Batch experiments were performed to study the applicability of the adsorbent by using fluoride contaminated groundwater collected from different wells. These results indicate that NC, PAC and $\mathrm{CAC}$ can be used as an effective, low-cost adsorbent to remove fluoride from groundwater.

\section{REFERENCES}

[1] J. Fawell J , Bailey K, Chilton J, E. Dahi, M. Lennon, P. Jackson, Fluoride in Drinking-water, 2006. doi:10.1007/BF01783490.

[2] E.D. J. Fawell, K. Bailey, J. Chilton, L.F. and Y. Magara, Fluoride in Drinking-water, the World Health Organization by IWA Publishing, Alliance House, 12 Caxton Street, London SW1H 0QS, UK, 2006.

[3] M.Tahir, H. Rasheed, Fluoride in the drinking water of Pakistan and the possible risk of crippling fluorosis, Drink. Water Eng. Sci. Discuss. 5 (2012) 495-514. doi:10.5194/dwesd-5-495-2012.

[4] T. Rango, A. Vengosh, G. Dwyer, G. Bianchini, Mobilization of arsenic and other naturally occurring contaminants in groundwater of the main ethiopian rift aquifers, Water Res. 47 (2013) 58015818. doi:10.1016/j.watres.2013.07.002.
[5] T. Rango, A. Vengosh, G. Dwyer, G. Bianchini, Mobilization of arsenic and other naturally occurring contaminants in groundwater of the Main Ethiopian Rift aquifers, J. Water Res. xxx (2013) 1-18.

[6] J. Zhu, H. Zhao, J. Ni, Fluoride distribution in electrocoagulation defluoridation process, Sep. Purif. Technol. 56 (2007) 184-191. doi:10.1016/j.seppur.2007.01.030.

[7] W. Driehaus, F. Dupont, Arsenic removal - Solutions for a world wide health problem using iron based adsorbents, J. Eur. dHydrologie. 36 (2005) 119-132.

[8] A. Saxena, M. Fujiki, R. Rai, S. Kim, G. Kwak, Highly sensitive and selective fluoride ion chemosensing, fluoroalkylated polysilane, Macromol. Rapid Commun. 25 (2004) 1771-1775

[9] M.F. Ahmed, An Overview of Arsenic Removal Technologies in Bangladesh and India, Civ. Eng. (2001) 251-269.

[10] S. Aredes, B. Klein, M. Pawlik, The removal of arsenic from water using natural iron oxide minerals, J. Clean. Prod. 29-30 (2012) 208-213.

[11] D. Mohan, M. Maruthamuthu, Studies on defluoridation of water by coal-based sorbents $\uparrow, 722$ (2001) 717-722. doi:10.1002/jctb.440.

12] J. Chu, J. Chen, C. Wang, P. Fu, Wastewater reuse potential analysis: Implications for China's water resources management, $\begin{array}{llll}\text { Water } & \text { Res. } & 38 & \text { (2004) }\end{array}$ doi:10.1016/j.watres.2004.04.002.

[13] E. Metcalf, H. Eddy, Wastewater engineering: treatment and reuse, 2003.

[14] V.M. Boddu, K. Abburi, J.L. Talbott, E.D. Smith, R. Haasch, Removal of arsenic (III) and arsenic (V) from aqueous medium using chitosan-coated biosorbent., Water Res. 42 (2008) 633-642.

[15] I. Ali, V.K. Gupta, Advances in water treatment by adsorption technology., Nat. Protoc. 1 (2006) 2661-2667.

[16] P. Chancellor, Defluoridation of water using inexpensive adsorbents, Fluoride. (2004) 163-171.

[17] H. Chiou, THE ADSORPTION OF FLUORIDE ION FROM AQUEOUS SOLUTION BY ACTIVATED ALUMINA, (2002) 349-360.

[18] M.J. Larsen, E.I. Pearce, S.J. Jensen, Defluoridation of water at high $\mathrm{pH}$ with use of brushite, calcium hydroxide, and bone char., J. Dent. Res. 72 (1993) 1519-1525. doi:10.1177/00220345930720111001.

[19] P.S. and S. Chowdhury, Insight Into Adsorption Thermodynamics, J. Hazard. Mater. 162 (2003) 440. doi:10.1007/978-3-642-30391-3. 
[20] Y. Fawell, J., Bailey, K., Chilton, J., Dahi, E., Fewtrell, L.and Magara, Fluoride in Drinking water. WHO- drinking water quality serious, (2006) 10-14.

[21] Kumar R. \& Chinnaiya N., Preparation and Characterization of Polymer Single Crystals for Use as Adsorbent, Environ. Eng. Manag. 19 (2009) 173-178.

[22] G. Alagumuthu, V. Veeraputhiran, R. Venkataraman, Adsorption Isotherms on Fluoride Removal : Batch Techniques, 2 (2010) 170185.

[23] J.A. Maciá-Agulló, B.C. Moore, D. Cazorla-Amorós, A. LinaresSolano, Activation of coal tar pitch carbon fibres: Physical activation vs. chemical activation, in: Carbon N. Y., 2004: pp. 1361-1364. doi:10.1016/j.carbon.2004.01.013.

[24] A. Tor, Removal of fluoride from an aqueous solution by using montmorillonite, $201 \quad$ 2606) 276. doi:10.1016/j.desal.2006.06.003

[25] R.A. Shawabkeh, M.F. Tutunji, Experimental study and modeling of basic dye sorption by diatomaceous clay, Appl. Clay Sci. 24 (2003) 111-120. doi:10.1016/S0169-1317(03)00154-6.

[26] G.W. Sears, Determination of Specific Surface Area of Colloidal Silica by Titration with Sodium Hydroxide, Anal. Chem. 28 (1956) 1981-1983. doi:10.1021/ac60120a048.

[27] E.D. Paul, C.E. Gimba, J.A. Kagbu, G.I. Ndukwe, F.G. Okibe, Spectrometric Determination of Fluoride in Water, Soil and Vegetables from the Precinct of River Basawa , Zaria , Nigeria, 1 (2011) 33-38

[28] F. Fufa, E. Alemayehu, B. Lennartz, Defluoridation of Groundwater Using Termite Mound, Water, Air, Soil Pollut. 224 (2013) 1552. doi:10.1007/s11270-013-1552-y.

[29] S. A. Akinyemi, A. Akinlua, L. F. Petrik and W. M. Gitari, Mineralogy and Geochemistry of Sub-Bituminous Coal and Its Combustion Products from Mpumalanga Province, South Africa, in: Anal. Chem., 2012: p. 56.

[30] S.K. Swain, T. Patnaik, V.K. Singh, U. Jha, R.K. Patel, R.K. Dey, Kinetics, equilibrium and thermodynamic aspects of removal of fluoride from drinking water using meso-structured zirconium phosphate, Chem. Eng. J. 171 (2011) 1218-1226. doi:10.1016/j.cej.2011.05.030.

[31] A.K. Yadav, C.P. Kaushik, A.K. Haritash, A. Kansal, N. Rani, Defluoridation of groundwater using brick powder as an adsorbent, J. Hazard. Mater. 128 (2006) 289-293. doi:10.1016/j.jhazmat.2005.08.006.

[32] A.R. Bhaumik, N.K. Mondal, B. Das, P. Roy, K.C. Pal, C. Das, Eggshell Powder as an Adsorbent for Removal of Fluoride from Aqueous Solution: Equilibrium, Kinetic and Thermodynamic Studies, E-Journal Chem. 9 (2012) 1457-1480.

[33] V. Tomar, D. Kumar, A critical study on efficiency of different materials for fluoride removal from aqueous media, Chem. Cent. J. 7 (2013) 1. doi:10.1186/1752-153X-7-51.

[34] A. Ramdani, S. Taleb, A. Benghalem, N. Ghaffour, Removal of excess fl uoride ions from Saharan brackish water by adsorption on natural materials, Desalination. 250 (2010) 408-413. doi:10.1016/j.desal.2009.09.066.

[35] A. Tor, N. Danaoglu, G. Arslan, Y. Cengeloglu, Removal of fluoride from water by using granular red mud: Batch and column studies, J. Hazard. Mater. 164 (2009) 271-278. doi:10.1016/j.jhazmat.2008.08.011.

[36] W. Tang, R. Zeng, Y. Feng, X. Li, W. Zhen, Removal of Cr ( VI ) from aqueous solution by nano-carbonate hydroxylapatite of different Ca / P molar ratios, Chem. Eng. J. 223 (2013) 340-346. doi:10.1016/j.cej.2013.02.094.

[37] I. Langmuir, The constitution and fundamental properties of solids and liquids. Part I. Solids., J. Am. Chem. Soc. 38 (1916) 22212295. doi:10.1021/ja02268a002.

[38] P.S. Kumar, K. Kirthika, EQUILIBRIUM AND KINETIC STUDY OF ADSORPTION OF NICKEL FROM AQUEOUS SOLUTION ONTO BAEL TREE LEAF POWDER, J. Eng. Sci. Technol. 4 (2009) 351-363.

[39] K. Vijayaraghavan, T.V.N. Padmesh, K. Palanivelu, M. Velan, Biosorption of nickel(II) ions onto Sargassum wightii: Application of two-parameter and three-parameter isotherm models, J. Hazard. Mater. 133 (2006) 304-308. doi:10.1016/j.jhazmat.2005.10.016

[40] K. State, E. State, K. State, Langmuir , Freundlich , Temkin and Dubinin - Radushkevich Isotherms Studies of Equilibrium Sorption of Zn 2 + Unto Phosphoric Acid Modified Rice Husk, 3 (2012) 3845 .
[41] Y. Çengeloğlu, E. Kır, M. Ersöz, Removal of fluoride from aqueous solution by using red mud, Sep. Purif. Technol. 28 (2002) 81-86. doi:http://dx.doi.org/10.1016/S1383-5866(02)00016-3.

[42] N. Medellin-Castillo, Adsorption of fluoride from water solution on bone char, Ind. .... (2007) 9205-9212. doi:10.1021/ie070023n.

[43] G. Lee, C. Chen, S.-T. Yang, W.-S. Ahn, Enhanced adsorptive removal of fluoride using mesoporous alumina, Microporous Mesoporous Mater. $127 \quad$ (2010) 152-156. doi:10.1016/j.micromeso.2009.07.007.

[44] V. Tomar, S. Prasad, D. Kumar, Adsorptive removal of fluoride from aqueous media using Citrus limonum (lemon) leaf, $\begin{array}{lllll}\text { Microchem. } & \text { J. } & 112 & \text { (2014) }\end{array}$ doi:http://dx.doi.org/10.1016/j.microc.2013.09.010.

[45] Y. Li, P. Zhang, Q. Du, X. Peng, T. Liu, Z. Wang, et al., Adsorption of fluoride from aqueous solution by graphene, J. Colloid Interface Sci. $363 \quad$ (2011) 348-354. doi:http://dx.doi.org/10.1016/j.jcis.2011.07.032. 